\title{
Effects of Intravenous Triacylglycerol Emulsions on Hepatic Metabolism and Blood Metabolites in Fasted Dairy Cows
}

\author{
D. G. Mashek, S. J. Bertics, and R. R. Grummer \\ Department of Dairy Science, University of Wisconsin, Madison 53706
}

\section{ABSTRACT}

The objective was to determine the effects of intravenous infusion of triacylglycerol (TAG) emulsions derived from different lipid sources on energy metabolism during a 4-d fast. Six nonpregnant, nonlactating multiparous Holstein cows were randomly assigned to treatments in a replicated $3 \times 3$ Latin Square design. Treatments included intravenous infusion of tallow, linseed oil, or fish oil emulsions at a rate of $0.54 \mathrm{~g}$ of TAG/kg of body weight per day; infusions were concurrent with a 4-d fast. The emulsions were administered for 20 to 30 min every $4 \mathrm{~h}$ throughout the 4 -d fast. Cows were fed ad libitum for $24 \mathrm{~d}$ between the fast/infusion periods. Infusion of tallow, linseed oil, or fish oil emulsions increased plasma concentrations of palmitic acid, linolenic acid, and eicosapentaenoic and docosahexaenoic acids, respectively. Infusion of linseed oil emulsion decreased plasma TAG concentrations compared with tallow and fish oil treatments, which were similar. Infusion of the tallow emulsion resulted in the highest concentrations of plasma nonesterified fatty acid (NEFA), insulin, and glucose, whereas the infusion derived from linseed oil had the lowest NEFA and $\beta$-hydroxybutyric acid concentrations. The different TAG emulsions had no effect on total or peroxisomal oxidation of $\left[1-{ }^{14} \mathrm{C}\right]$ oleic acid in liver homogenates. Liver TAG content increased $12.0,7.8$, and $14.1 \mu \mathrm{g} / \mu \mathrm{g}$ of DNA during the fast for tallow, linseed oil, and fish oil treatments, respectively; linseed oil was different from fish oil and tended to be different from tallow.

(Key words: fatty liver, energy metabolism, bovine)

Abbreviation key: ASP $=$ acid-soluble products, PUFA = polyunsaturated fatty acids, TAG = triacylglycerol.

\section{INTRODUCTION}

Bovine fatty liver remains a common occurrence with recent estimates showing that over half of all cows expe-

Received April 27, 2004.

Accepted September 24, 2004.

Corresponding author: Ric R. Grummer; e-mail: rgrummer@ wisc.edu. rience moderate to severe hepatic triacylglycerol (TAG) accumulation at parturition (Jorritsma et al., 2001). Research from our laboratory has shown that TAG accumulation in monolayer cultures of bovine hepatocytes decreases gluconeogenesis (Cadorniga-Valino et al., 1997) and ureagenesis (Strang et al., 1998). Therefore, identification of strategies to alter hepatic lipid metabolism and alleviate fatty liver remains a priority.

Ruminant liver removes fatty acids from the bloodstream in proportion to their concentration (Emery et al., 1992). During times of elevated fat mobilization and subsequent hepatic uptake of fatty acids, a major metabolic route of hepatic fatty acid metabolism is storage as TAG. However, until recently it was not known if hepatic metabolism of fatty acids differs based upon fatty acid chain length or degree of unsaturation. Mashek and Grummer (2003) showed that individual fatty acids influence lipid and glucose metabolism in monolayer cultures of bovine hepatocytes. Specifically, linolenic acid appeared to be one of the most beneficial fatty acids because its addition to media resulted in decreased TAG concentrations and one of the highest rates of gluconeogenesis compared with other long chain fatty acids. In contrast, media containing docosahexaenoic acid, a fatty acid found predominantly in fish oil, increased cellular TAG content and decreased rates of gluconeogenesis.

The effects of different fatty acids on energy and hepatic metabolism in vivo have not been studied in ruminants. Although technologies to minimize rumen biohydrogenation of fatty acids have been developed, differences in rates of biohydrogenation and postrumen digestibility between fatty acids confound comparison of feeding individual fatty acids on postabsorptive metabolism. Additionally, successful infusion of individual fatty acids directly into the bloodstream has not been demonstrated. Therefore, we developed TAG emulsions for intravenous administration to test the effects of lipid sources varying in fatty acid composition on hepatic and whole-body energy metabolism during a 4-d fast in dairy cows.

\section{MATERIALS AND METHODS}

\section{Reagents}

Tallow (HRR Enterprises, Inc, Chicago, IL), linseed oil (Archer Daniels Midland, Decatur, IL), and menha- 
den fish oil (Omega Protein, Inc., Hammond, LA) of the highest purities were donated. Lecithin (60\% purity) was purchased from ICN Chemicals (Irvine, CA), BSA from Intergen (Purchase, NY) and $\left[1-{ }^{14} \mathrm{C}\right]$ oleic acid from American Radiolabeled Chemicals, Inc. (St. Louis, MO). All other chemicals were from Sigma Chemical (St. Louis, MO).

\section{Emulsion Preparation}

Fish oil contained $500 \mathrm{ppm}$ of ethoxyquin to protect against peroxidation of fatty acids. The same amount of ethoxyquin was added to tallow and linseed before the emulsification process to equalize antioxidant concentrations amongst emulsions. In separate containers, $200 \mathrm{~g}$ of lipid source or $765 \mathrm{~mL}$ of water were heated to approximately $70^{\circ} \mathrm{C}$. Lecithin $(12 \mathrm{~g})$ was added to the water and the mixture was homogenized in a Hamilton Beach Blendmaster blender (Washington, NC) at high speed for $1 \mathrm{~min}$. Glycerol (50 g) was then added to the heated lipid followed by the lecithin and water mixture. A coarse emulsion was prepared by homogenizing the mixture for $2 \mathrm{~min}$ in the blender. Subsequently, the emulsion was passed through an EmulsiFlex-C50 homogenizer (Avestin, Inc., Ottawa, CA) 3 times at approximately 15,000 to $17,000 \mathrm{psi}$. The recipient flask was placed in cold water during the homogenization process to cool the emulsion. After adjusting the $\mathrm{pH}$ to 8.3 with $1 \mathrm{~N} \mathrm{NaOH}$, approximately $500 \mathrm{~mL}$ of emulsion was placed in a 1-L Erlenmeyer flask and autoclaved for $25 \mathrm{~min}$ at $21 \mathrm{psi}$ and $121^{\circ} \mathrm{C}$. The flasks were then cooled in water and the contents were aseptically transferred to sterile $500-\mathrm{mL}$ bottles and stored at $4^{\circ} \mathrm{C}$ with the exception of emulsions containing tallow, which were never allowed to cool below room temperature and were stored at $37^{\circ} \mathrm{C}$ to prevent creaming.

\section{Animals and Treatments}

Six multiparous, nonpregnant, nonlactating Holstein cows weighing $735 \pm 71 \mathrm{~kg}$ (mean $\pm \mathrm{SD}$ ) were randomly assigned to treatments in a replicated $3 \times 3$ Latin Square design. The average age of cows was $4.7 \mathrm{yr}$, and average BCS was 3.6. Treatments consisted of an intermittent intravenous infusion of a $20 \%$ TAG emulsion derived from tallow, linseed oil, or fish oil. Tallow was chosen as a control treatment because it represents the fatty acid composition normally found in ruminant animals. Additionally, the use of tallow maintains isocaloric conditions across treatments. The emulsions were given via drip infusion over a 20 - to 30 -min period every $4 \mathrm{~h}$ at a rate of $0.54 \mathrm{~g}$ of TAG/ $\mathrm{kg}$ of BW daily for $4 \mathrm{~d}$. For example, a 735-kg cow would receive $331 \mathrm{~mL}$ of emulsion (66 g of TAG) every $4 \mathrm{~h}$, or $1986 \mathrm{~mL}$ (396 $\mathrm{g}$ of TAG) per day. This dose (396 $\mathrm{g}$ of TAG per day) would be equivalent to a $735-\mathrm{kg}$ cow eating $2 \%$ of its BW of a diet containing 2.7\% (DM basis) dietary TAG without discounting differences in digestibility or changes in fatty acid composition due to biohydrogenation. Therefore, the amount of TAG infused is within physiological ranges of dietary supplemented fat (NRC, 2001). Concurrent with the infusions, cows were fasted to increase NEFA mobilization and induce fatty liver. Cows were given $24 \mathrm{~d}$ between infusion periods to allow liver TAG to return to basal levels, which was confirmed by hepatic TAG analysis. Between infusion periods, cows were fed a basal diet consisting of alfalfa/grass hay and a supplement containing corn grain, soy hulls, and minerals and vitamins to meet or exceed NRC recommendations (NRC, 2001). During infusion periods, cows were given approximately $100 \mathrm{~g}$ of the supplement with high concentrations of minerals and vitamins to meet their daily requirements. Cows were housed on a bedded pack between infusions and in tie stalls during the infusion period. Cows were allowed to exercise in an open lot for $2 \mathrm{~h} / \mathrm{d}$ during the infusion period and were offered water ad libitum. The University of Wisconsin Animal Care and Use Committee approved all animalrelated procedures.

\section{Sampling and Analysis}

Approximately $4 \mathrm{~d}$ before the start of each infusion period, cows were weighed to determine the proper dosage of emulsion for each animal. Cows were biopsied for liver tissue $2 \mathrm{~d}$ before the start of the infusion period and immediately after the last blood sample $(96 \mathrm{~h})$ as previously described (Vazquez-Anon et al., 1994). A portion of the liver tissue was rinsed in saline, flash frozen in liquid $\mathrm{N}$ and stored at $-20^{\circ} \mathrm{C}$ for future analysis. Another portion of liver was placed in oxygenated PBS on ice and transported to the laboratory for in vitro measurements described below. Bilateral jugular catheters were inserted into all cows the day before initiation of infusions. Cows were given 10,000 $\mathrm{U}$ of penicillin G (G. C. Hanford Mfg. Co., Syracuse, NY) per day as a prophylactic following catheter insertion until $3 \mathrm{~d}$ after the last day of infusions.

Approximately $10 \mathrm{~mL}$ of blood were sampled every 8 $\mathrm{h}$ throughout the infusion period and placed in Vacutainer tubes containing sodium heparin (Becton Dickinson, Franklin Lakes, NJ). Tubes were transported to the laboratory on ice, centrifuged, and plasma was harvested and stored at $-20^{\circ} \mathrm{C}$.

Fresh liver samples were homogenized with 4 strokes of a Potter-Elvehjem Teflon pestle. Media preparation and measurement of total and peroxisomal oxidation of liver homogenates was done as previously described 
(Grum et al., 1994) except that $\left[1-{ }^{14} \mathrm{C}\right]$ oleic acid was used in place of $\left[1-{ }^{14} \mathrm{C}\right]$ palmitic acid. This procedure utilizes antimycin $\mathrm{A}(50 \mu M)$ and rotenone $(10 \mu M)$ to inhibit mitochondrial oxidation. Therefore, peroxisomal oxidation is calculated as total oxidation minus oxidation in the presence of the mitochondrial inhibitors. The metabolism of $\left[1-{ }^{14} \mathrm{C}\right]$ oleic acid to $\mathrm{CO}_{2}$ and acid-soluble products (ASP) was measured over $30 \mathrm{~min}$. An aliquot of the homogenate was frozen at $-20^{\circ} \mathrm{C}$ and analyzed for protein (BCA Protein Assay, Pierce Chemical Co., Rockford, IL).

Frozen liver samples were thawed, extracted (Folch et al., 1957), and analyzed for TAG content using a colorimetric assay (Foster and Dunn, 1973). Aliquots of the lipid extract were separated by TLC using petroleum ether:diethyl ether:acetic acid (80:20:1) as the mobile phase. Spots corresponding to TAG were removed, extracted with chloroform:methanol (2:1), and methylated (Sukhija and Palmquist, 1988) for determination of fatty acid composition by gas chromatography. The method of LaBarca and Paigen (1980) was used to determine DNA concentrations.

Plasma samples were analyzed for NEFA (NEFA-C kit; Wako Fine Chemical Industries USA, Dallas, TX), glucose (Sigma procedure 510; Sigma Chemical Co.), BHBA (Sigma procedure 319; Sigma Chemical Co.), triacylglycerol and glycerol (Kit 337-B; Sigma Chemical Co.), and insulin (Coat-A-Count; Diagnostic Products Corp., Los Angeles, CA). Plasma samples from 72, 80, 88 , and $96 \mathrm{~h}$ after initiation of treatments were pooled and extracted (Dole, 1956). Neutral lipids were then separated by TLC and spots corresponding to the fatty acid fraction were removed, extracted with chloroform:methanol (2:1), and methylated (Sukhija and Palmquist, 1988) for determination of fatty acid composition by gas chromatography.

\section{Statistical Analysis}

Data were analyzed using the Mixed procedure of SAS (SAS Institute, 2001). For repeated measurements, the model included a covariate, fixed effects of period, treatment, and time, random effects of cow (square), 2-way interactions of fixed effects, and the residual error. The covariate and interactions were removed if they were not significant $(P<0.10)$ in the model. For dependent variables that were not repeated, time and interactions with time was removed from the above model. If treatment was significant in the model $(P<0.05)$, the PDIFF procedure was used to determine treatment differences. The SLICE procedure of SAS was used to compare individual time points if there were significant treatment $\times$ time interactions. Signifi-
Table 1. Fatty acid composition of triacylglycerol emulsions.

\begin{tabular}{lccc}
\hline Fatty acid & Tallow & Linseed oil & Fish oil \\
\cline { 2 - 4 } & & (\% of total $)$ & \\
\cline { 2 - 4 } $14: 0$ & 3.11 & 0.04 & 7.4 \\
$16: 0$ & 25.98 & 6.00 & 20.51 \\
$16: 1$ & 3.17 & 0.08 & 10.02 \\
$17: 0$ & 1.30 & 0.04 & 0.65 \\
$18: 0$ & 17.87 & 4.13 & 4.15 \\
$18: 1$ & 43.09 & 20.96 & 15.21 \\
$18: 2$ & 2.84 & 16.81 & 3.11 \\
$18: 3$ & 0.43 & 51.13 & 1.70 \\
$20: 1$ & 0.22 & 0.24 & 1.75 \\
$20: 4$ & 0.20 & 0.12 & 1.03 \\
$20: 5$ & $\mathrm{ND}$ & 0.12 & 13.55 \\
$22: 6$ & $\mathrm{ND}$ & 0.11 & 18.46 \\
Other & 1.79 & 0.22 & 2.46 \\
\hline
\end{tabular}

${ }^{1} \mathrm{ND}=$ Not detected .

cance was declared at $P<0.05$ and trends toward significance were declared at $P<0.10$.

\section{RESULTS AND DISCUSSION}

Previous studies involving intravenous TAG emulsions have shown that TAG derived from emulsions are metabolized in a similar manner to chylomicrons (Hultin et al., 1995; Ferezou and Bach, 1999). Administration of heparin concurrently with emulsion infusion causes a release of plasma lipoprotein lipase and an increase in circulating TAG lipolysis and plasma NEFA concentrations (Hultin et al., 1992). We tested the ability of heparin to cause TAG hydrolysis in the bovine, but found that the increase in NEFA following heparin administration was attenuated with time. Frequent injections of heparin can deplete lipoprotein lipase activity and thus, diminish the ability of heparin to elicit changes in TAG lipolysis and increase NEFA (Nestel, 1970). Therefore, we did not use heparin in the current studies and anticipated that the incorporation of emulsion fatty acids into TAG stores and their subsequent turnover would yield changes in blood fatty acid profiles reflecting those of the emulsion administered.

\section{Fatty Acid Composition of Emulsions, Plasma NEFA, and Hepatic TAG}

Fatty acid composition of TAG emulsions is shown in Table 1. The most common fatty acids in ruminants, C16:0, C18:0, and C18:1, comprised $86.9 \%$ of the fatty acids in the tallow emulsion, whereas C18:3 comprised $0.43 \%$, and $\mathrm{C} 20: 5$ and $\mathrm{C} 22: 6$ were not detectable. In the linseed oil emulsion, C18:3 accounted for $51.1 \%$ and total polyunsaturated fatty acids (PUFA) accounted for $68.5 \%$ of all fatty acids. The n-3 PUFA, C20:5 and C22:6, comprised 13.6 and $18.5 \%$ of total fatty acids in the fish 
Table 2. Least squares means of fatty acid composition of plasma NEFA over the last $24 \mathrm{~h}$ of a 4 -d fast concurrent with intravenous infusions of tallow, linseed oil, or fish oil emulsions.

\begin{tabular}{lcccc}
\hline Fatty acid & Tallow & Linseed oil & Fish oil & SEM \\
\cline { 2 - 3 } & \multicolumn{3}{c}{$(\%$ of total $)$} & \\
\cline { 2 - 4 } $16: 0$ & $22.30^{\mathrm{a}}$ & $20.54^{\mathrm{b}}$ & $21.00^{\mathrm{b}}$ & 0.37 \\
$16: 1$ & 3.04 & 2.45 & 3.05 & 0.22 \\
$18: 0$ & 21.83 & 22.08 & 21.96 & 1.05 \\
$18: 1$ & 39.46 & 37.24 & 38.08 & 1.90 \\
$18: 2$ & 6.84 & 7.56 & 8.11 & 0.67 \\
$18: 3$ & $1.69^{\mathrm{b}}$ & $5.99^{\mathrm{a}}$ & $2.51^{\mathrm{b}}$ & 0.67 \\
$20: 5$ & $\mathrm{ND}^{1}$ & $\mathrm{ND}$ & 2.62 & 0.17 \\
$22: 6$ & $\mathrm{ND}^{\mathrm{n}}$ & $\mathrm{ND}$ & 1.99 & 0.26 \\
Other & 3.65 & 3.28 & 2.50 & 0.37 \\
\hline
\end{tabular}

${ }^{\mathrm{a}, \mathrm{b}}$ Means with unlike superscripts differ $(P<0.05)$.

${ }^{1} \mathrm{ND}=$ Not detected.

oil emulsion. The fatty acid composition of all emulsions mirrored the composition of lipid sources (data not shown), which suggests that the emulsification and sterilization process had minimal effects on fatty acid composition.

The fatty acid profiles of plasma NEFA are shown in Table 2. Infusion of the tallow emulsion increased $(P<$ 0.05 ) the proportion of $\mathrm{C} 16: 0$ in plasma NEFA compared with the linseed and fish oil emulsions. As expected, infusion of the linseed oil emulsion increased $(P<0.05)$ C18:3 in plasma NEFA compared with tallow or fish oil emulsions. The C20:5 and C22:6 fatty acids were not detected in plasma of cows receiving tallow or linseed oil emulsions, but represented 2.62 and $1.99 \%$ of plasma NEFA of cows receiving fish oil infusions.

Infusion of the tallow emulsion increased the concentration of C18:1 in hepatic TAG compared with infusions of linseed and fish oil emulsions $(P<0.01$; Table 3 ). Hepatic concentrations of C18:3 were increased by infusion of linseed oil emulsions compared with infusions of either tallow or fish oil $(P<0.05)$. Infusion of fish oil resulted in $\mathrm{C} 20: 5$ and $\mathrm{C} 22: 6$ comprising $5 \%$ of hepatic TAG fatty acids, whereas these fatty acids were not detected in other samples.

\section{Plasma Metabolite and Hormone Concentrations}

Linseed oil treatment significantly reduced plasma TAG concentrations compared with tallow or fish oil, which were not different from each other (Figure 1). Plasma TAG concentrations decreased at 8 and $16 \mathrm{~h}$, especially for the tallow treatment. This transient decrease may have been a result of decreased intestinal TAG output following the initiation of a fast (Pullen et al., 1988). Previous research in rodents has shown that linseed oil, and polyunsaturated fats in general, decrease plasma TAG concentrations because of changes in hepatic TAG synthesis and secretion (Rustan et al., 1992; Takeuchi et al., 2001). Additionally, TAG emulsions derived from different lipid sources may have different clearance rates. To the best of our knowledge no such comparisons have been done with the lipid sources used in the current study.

There were no significant differences in plasma glycerol concentrations between emulsion types, although a treatment $\times$ time interaction was significant $(P<0.05$; Figure 2). Analysis of individual time points revealed that cows on the tallow treatment had increased glycerol at some of the later times including 56 and $80 \mathrm{~h}$ after initiation of the infusion. As expected, glycerol concentrations increased gradually over the infusion period, likely reflective of increased adipose tissue lipolysis. Similar to glycerol, plasma NEFA concentrations increased during the infusion period (Figure 3). Cows on the linseed oil treatment had significantly lower plasma NEFA concentrations than cows on the tallow treatment $(P<0.05)$, but were not different from the fish oil treatment. These data are supported by the increase in plasma glycerol at several time points for the tallow treatment, indicating increased lipolysis and decreased

Table 3. Least squares means of fatty acid composition of hepatic triacylglycerol before (pretreatment) and immediately after a 4-d fast concurrent with intravenous infusions of tallow, linseed oil, or fish oil emulsions.

\begin{tabular}{|c|c|c|c|c|c|}
\hline \multirow[b]{2}{*}{ Fatty acid } & \multirow{2}{*}{$\begin{array}{c}\text { Pre- } \\
\text { treatment }\end{array}$} & \multicolumn{3}{|c|}{ Treatment } & \multirow[b]{2}{*}{ SEM } \\
\hline & & Tallow & Linseed oil & Fish oil & \\
\hline & & & l) & & \\
\hline $16: 0$ & 30.88 & 29.44 & 26.10 & 26.58 & 2.41 \\
\hline $16: 1$ & 4.88 & 2.34 & 2.75 & 2.16 & 0.45 \\
\hline 18:0 & 12.30 & 7.45 & 7.62 & 5.88 & 1.32 \\
\hline $18: 1$ & 27.27 & $35.43^{\mathrm{a}}$ & $26.10^{\mathrm{b}}$ & $28.56^{\mathrm{b}}$ & 1.43 \\
\hline 18:2 & 7.32 & 16.70 & 13.58 & 17.84 & 4.21 \\
\hline $18: 3$ & 1.85 & $4.22^{\mathrm{b}}$ & $11.27^{\mathrm{a}}$ & $4.34^{\mathrm{b}}$ & 1.89 \\
\hline $20: 5$ & $\mathrm{ND}^{1}$ & ND & ND & 4.69 & 0.76 \\
\hline $22: 6$ & ND & ND & ND & 5.01 & 0.71 \\
\hline
\end{tabular}

${ }^{\mathrm{ab}}$ Means of treatments with unlike superscripts differ $(P<0.05)$.

${ }^{1} \mathrm{ND}=$ Not detected. 




Figure 1. Effects of triacylglycerol (TAG) emulsions derived from tallow, linseed oil and fish oil on plasma TAG concentrations. Significant effects in the model: treatment $(P<0.01)$, treatment $\times$ time $(P<0.01)$; significant contrasts: fish vs. linseed $(P<0.001)$, linseed vs. tallow $(P<0.01)$. Data represent least squares means and standard error of the mean.

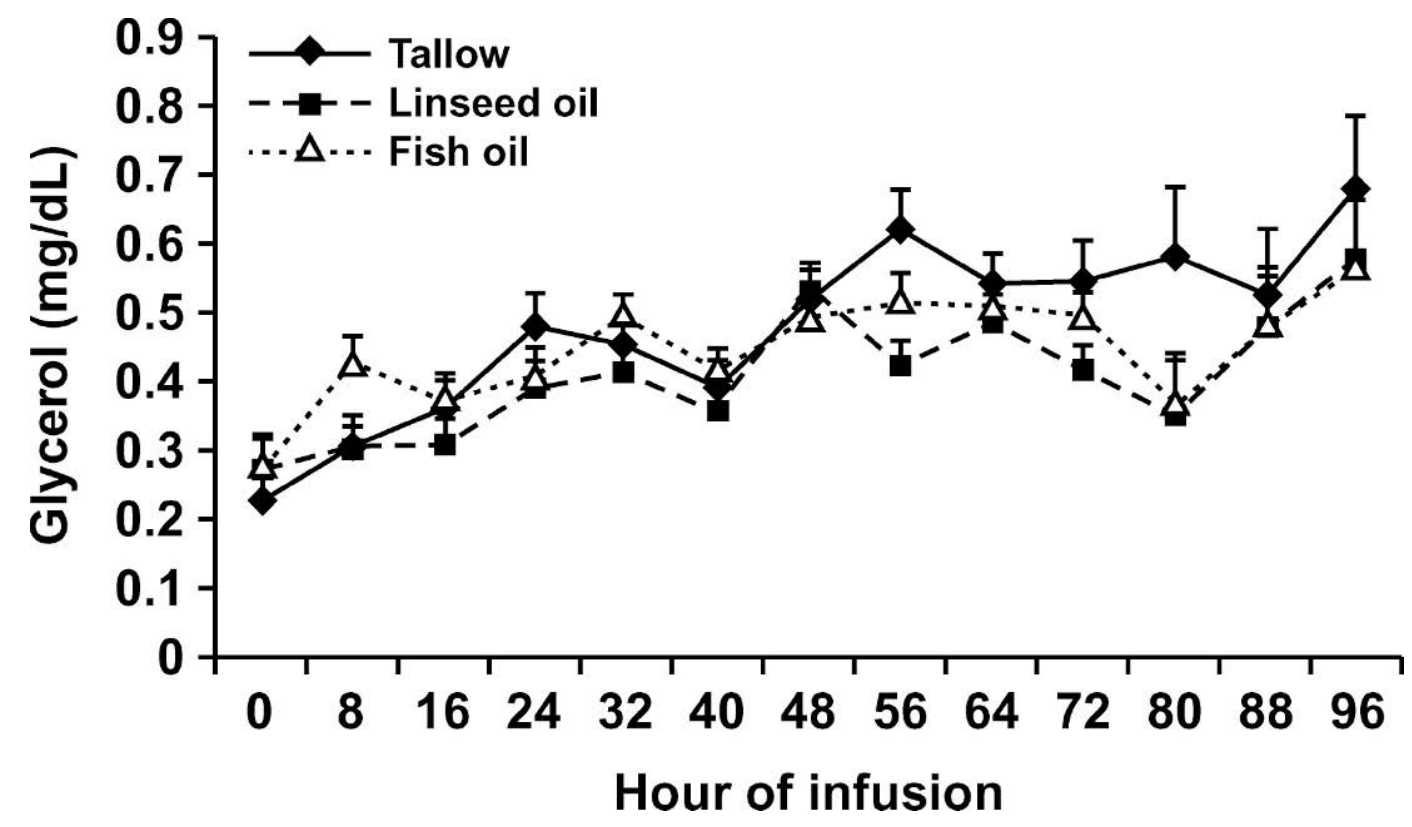

Figure 2. Effects of triacylglycerol emulsions derived from tallow, linseed oil, and fish oil on plasma glycerol concentrations. Significant effects in the model: treatment $\times$ time $(P<0.05)$. Data represent least squares means and standard error of the mean. 


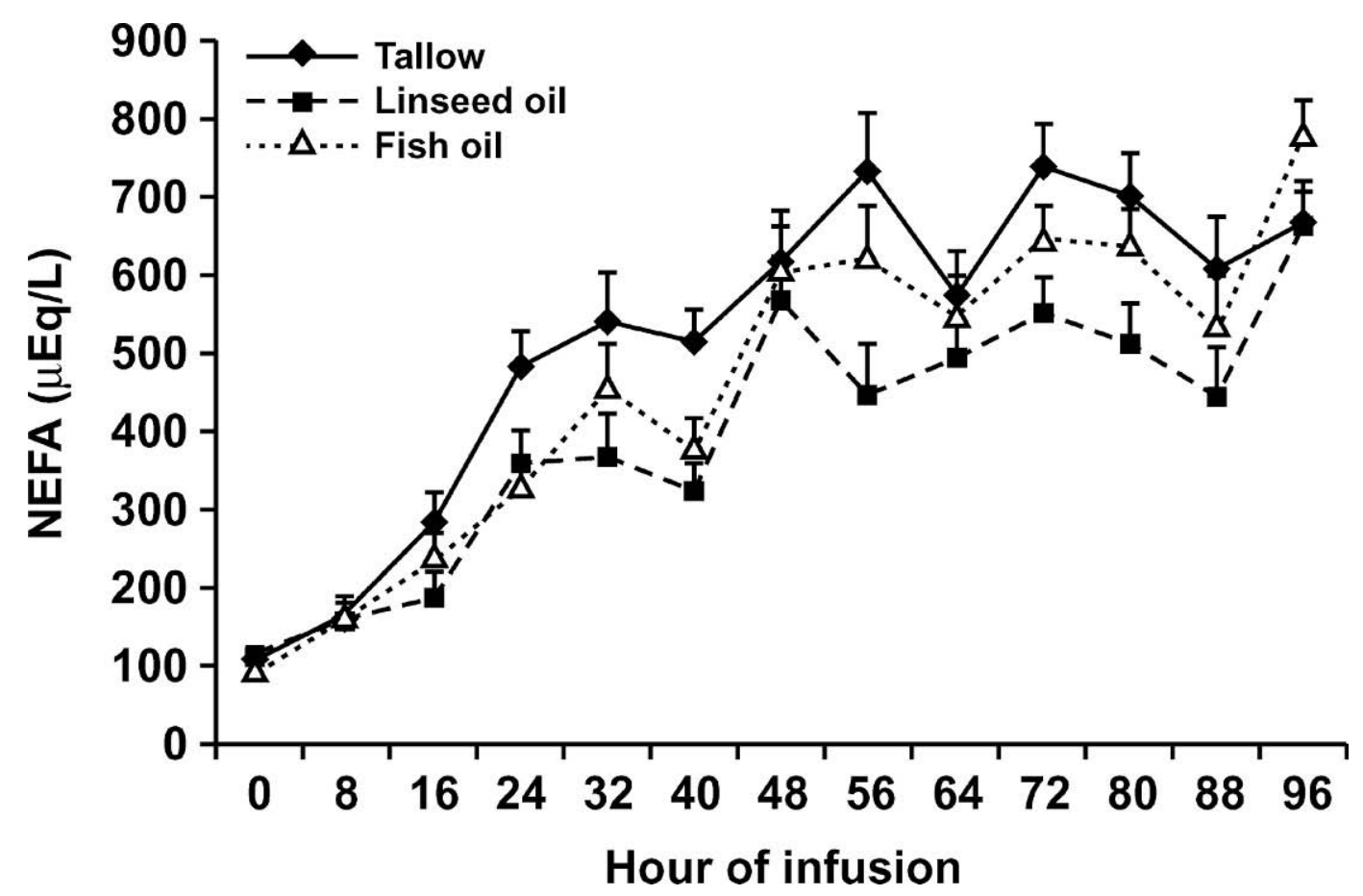

Figure 3. Effects of triacylglycerol emulsions derived from tallow, linseed oil, and fish oil on plasma NEFA concentrations. Significant effects in the model: treatment $(P<0.05)$, treatment $\times$ time $(P<0.0001)$; significant contrasts: linseed vs. tallow $(P<0.05)$. Data represent least squares means and standard error of the mean.

re-esterification of fatty acids in adipose tissue. Plasma NEFA concentrations were similar in rodents following infusion of either linseed or fish oil emulsions (Yeh et al., 1998). The exact mechanism for the decreased plasma NEFA concentrations in the current study is unknown, but is likely a result of changes in adipose tissue metabolism, because all animals should have been in identical energy balance. A decrease in hydrolysis of the emulsion could have caused the lower plasma NEFA concentrations in cows given linseed oil. However, the linseed oil treatment resulted in the lowest plasma TAG concentrations, which suggests that changes in emulsion hydrolysis did not impact plasma NEFA concentrations.

Because NEFA are substrates for ketogenesis, changes in ketone bodies would be expected based upon differences observed in plasma NEFA. As shown in Figure 4, linseed oil infusions resulted in the lowest plasma BHBA concentrations, which were lower than tallow $(P<0.01)$ and fish oil $(P<0.0001)$. In addition, plasma BHBA concentrations tended to be lower for tallow compared with fish oil infusions $(P<0.10)$.

There tended $(P<0.10)$ to be a main effect of emulsion type on plasma glucose concentrations with plasma glucose concentrations being greater in cows on the tallow treatment than fish oil or linseed oil $(P<0.05$; Figure $5)$. Previous in vitro studies have shown that linolenic acid, the predominant fatty acid in linseed oil, increased hepatic gluconeogenesis compared with most other long chain fatty acids, especially those found in fish oil (Mashek and Grummer, 2003). Feeding linseed oil or a linseed and fish oil mixture to cows increased plasma glucose concentrations compared with a control treatment containing mostly saturated fatty acids (Petit et al., 2002). Plasma insulin concentrations decreased over the infusion period, but there was no main effect of emulsion type (Figure 6 ). A treatment $\times$ time interaction indicates that cows on the tallow treatment had lower plasma insulin concentrations at time 0 and higher values during the last several sampling points compared with cows receiving linseed or fish oil emulsions. Both in vitro and in vivo studies in rodents have shown that saturated fatty acids are more potent stimulators of glucose-induced insulin secretion compared with unsaturated fatty acids (Dobbins et al., 2002; Gravena et al., 2002). Additionally, saturated fatty acids induce insulin resistance and inhibit glucose uptake in adipocytes compared with unsaturated fatty acids (Hunnicutt et al., 1994). Therefore, an increase in saturated fatty acids, such as in the tallow treatment, may have caused increased plasma insulin, glucose, and NEFA concentrations through increased insulin secretion and decreased insulin-induced glucose uptake and suppression of lipolysis in adipose tissue. 




Figure 4. Effects of triacylglycerol emulsions derived from tallow, linseed oil, and fish oil on plasma BHBA concentrations. Significant effects in the model: treatment $(P<0.001)$, treatment $\times$ time $(P<0.0001)$; significant contrasts: fish vs. linseed $(P<0.0001)$, fish vs. tallow $(P<0.10)$, linseed vs. tallow $(P<0.01)$. Data represent least squares means and standard error of the mean.

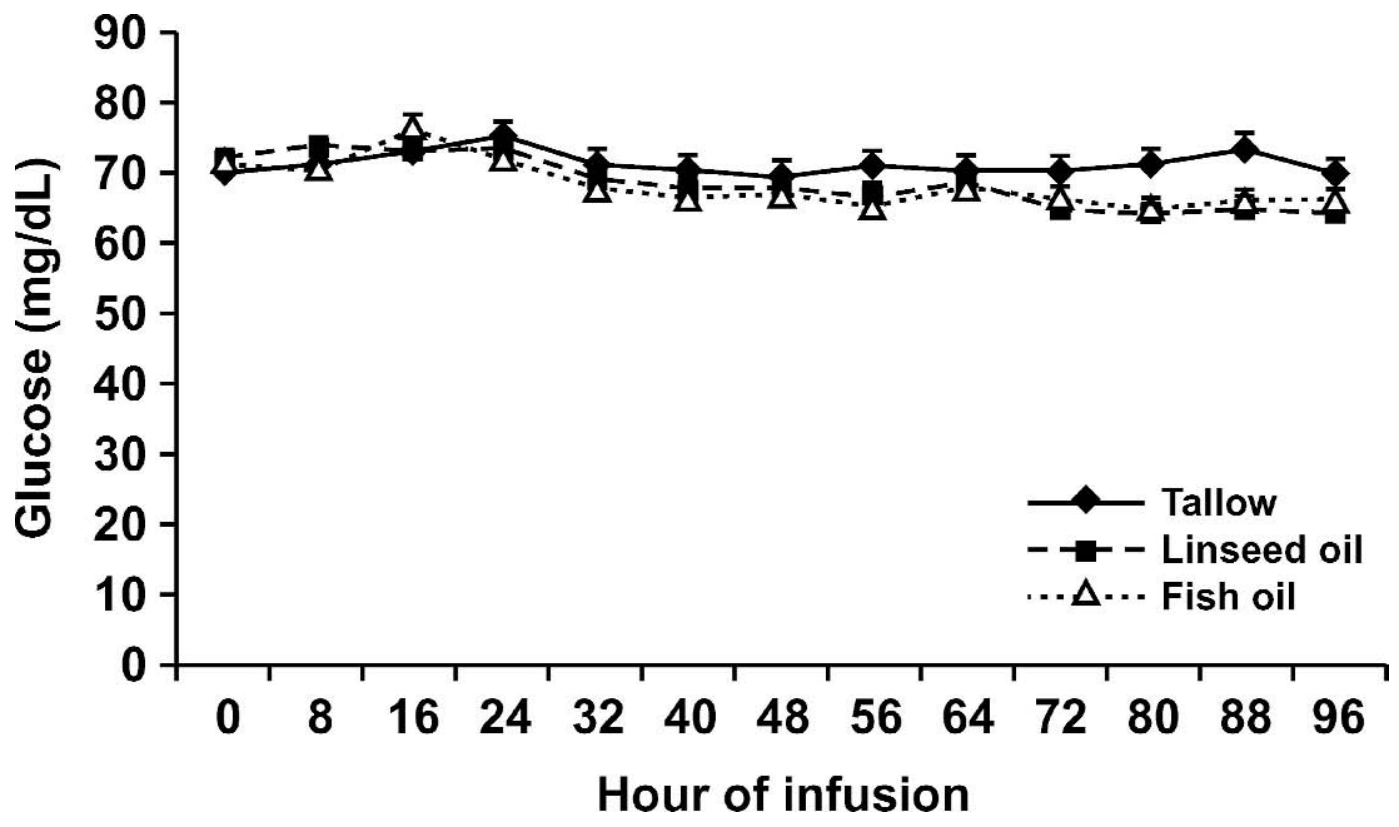

Figure 5. Effects of triacylglycerol emulsions derived from tallow, linseed oil, and fish oil on plasma glucose concentrations. Significant effects in the model: treatment $(P<0.10)$; significant contrasts: fish vs. tallow $(P<0.05)$, linseed vs. tallow $(P<0.05)$. Data represent least squares means and standard error of the mean. 


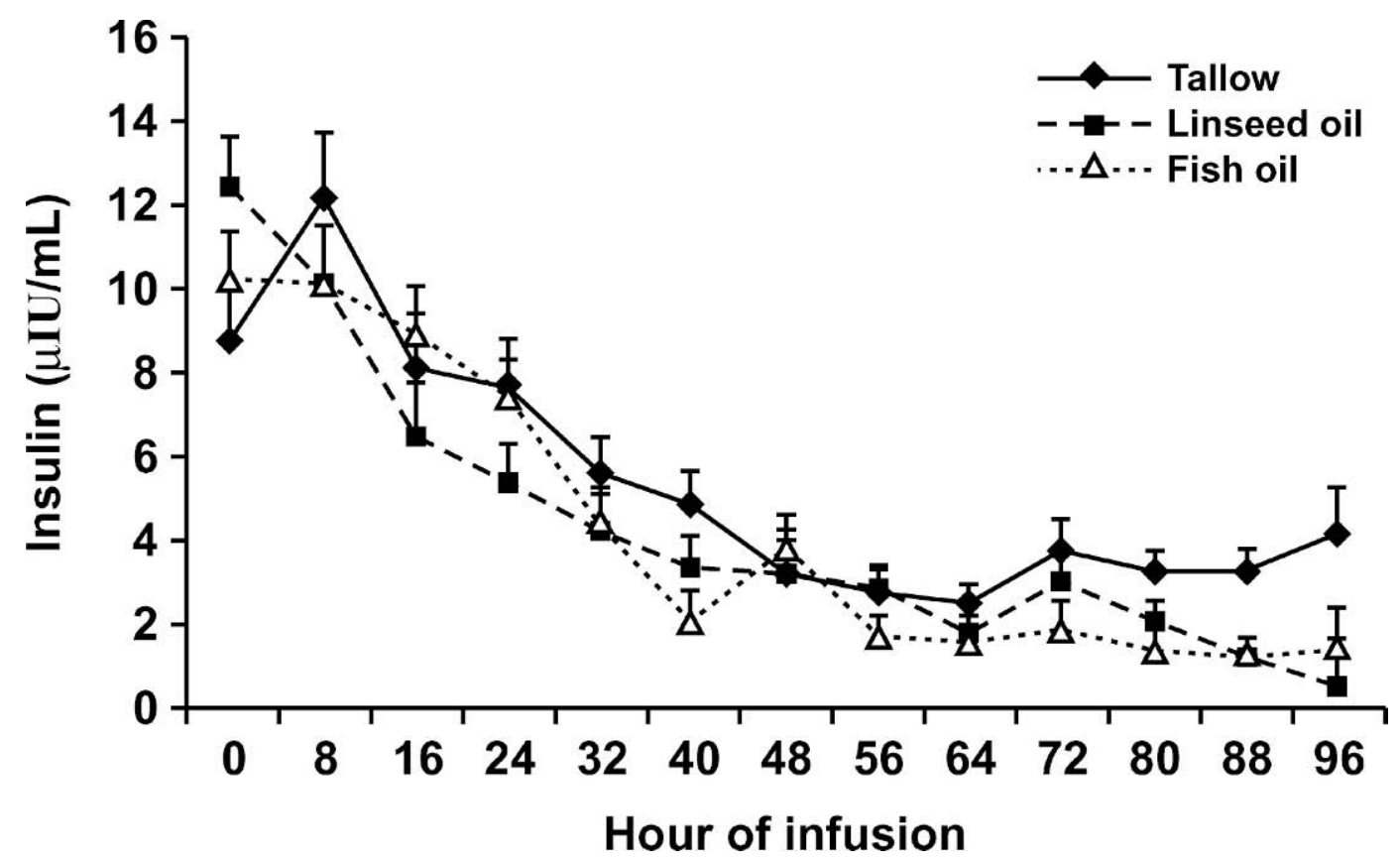

Figure 6. Effects of triacylglycerol emulsions derived from tallow, linseed oil, and fish oil on plasma insulin concentrations. Significant effects in the model: treatment $\times$ time $(P<0.05)$. Data represent least squares means and standard error of the mean.

\section{In Vitro Hepatic Oxidation}

The fish oil emulsions numerically increased total oxidation to ASP by 37 and $25 \%$ compared with pretreatment and tallow infusion, respectively. However, we were unable to detect significant effects of different TAG emulsions on total oxidation or peroxisomal oxidation of oleic acid to $\mathrm{CO}_{2}$ and ASP (Table 4). Similar to Grum et al., (1994), we found that peroxisomal oxidation accounts for approximately 50\% of the first round of fatty acid oxidation. It is surprising that the PUFA had no effect on peroxisomal oxidation. In general, PUFA are thought to increase peroxisomal proliferation and oxidation because of their binding to peroxisome proliferator-activated receptors and subsequently stim- ulation of peroxisomal proliferation (Sessler and Ntambi, 1998).

\section{Liver TAG Content}

As expected, liver TAG content increased during the 4-d fast (Figure 7). The increase in liver TAG for the linseed oil treatment was significantly different from fish oil $(P<0.05)$ and tended to be different from tallow $(P<0.10)$. There was no statistical difference in hepatic TAG changes between fish oil and tallow treatments. Previous research with monolayer cultures of bovine hepatocytes has shown that linolenic acid decreased liver TAG content compared with other long chain fatty acids when cells were exposed to similar fatty acid con-

Table 4. Least squares means of total and peroxisomal oxidation of $\left[1-{ }^{14} \mathrm{C}\right]$ oleic acid in liver homogenates before (pretreatment) and immediately after the 4-d fast concurrent with intravenous infusions of tallow, linseed oil, or fish oil emulsions. ${ }^{1}$

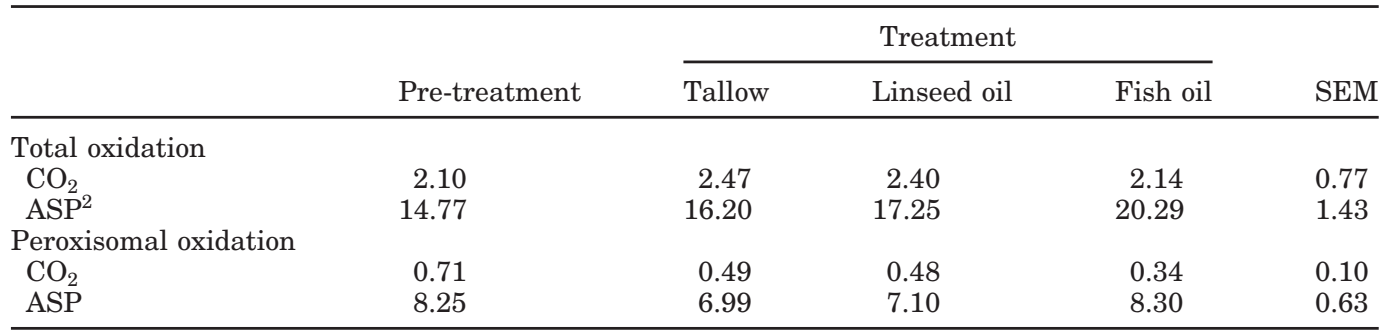

${ }^{1}$ Data are expressed as $\mu \mathrm{mol} / \mu \mathrm{g}$ of protein per $30 \mathrm{~min}$.

${ }^{2} \mathrm{ASP}=$ Acid-soluble products. 


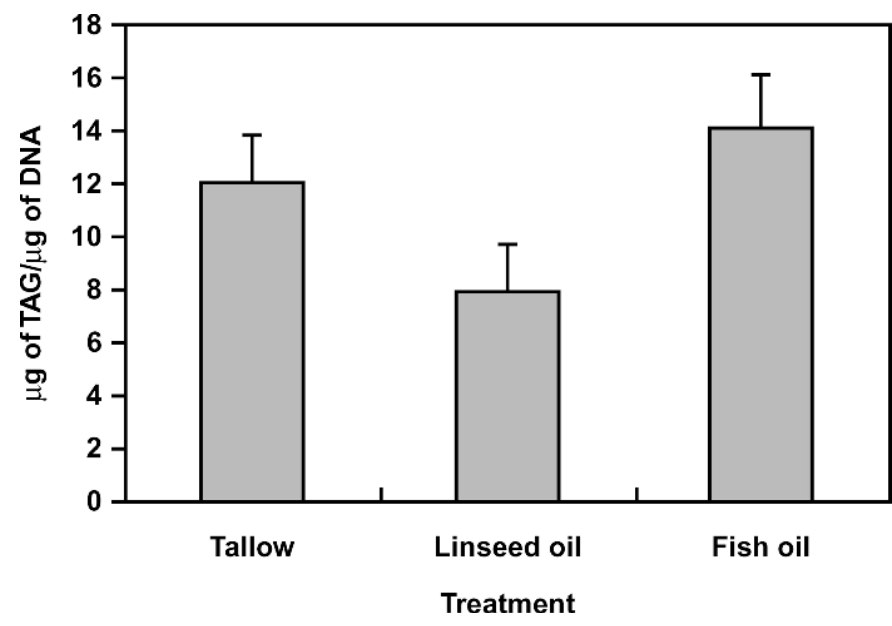

Figure 7. Effects of triacylglycerol emulsions derived from tallow, linseed oil, and fish oil on liver TAG content immediately after the 4-d fast and infusion period. Linseed was significantly different from fish oil $(P<0.05)$ and tended to be different from tallow $(P<0.10)$. There was no difference between tallow and fish oil. Data represent least squares means and standard error of the mean.

centrations (Mashek and Grummer, 2003). In the same study, docosahexaenoic acid increased TAG content in hepatocytes. In the current study the plasma NEFA concentrations differed among treatments. It is likely that the lower liver TAG concentrations may have resulted from lower plasma NEFA concentrations in cows on the linseed treatment. Therefore, we calculated the potential contribution of plasma NEFA toward liver TAG. For example, plasma NEFA concentrations averaged 397 and $516 \mu M$ across the 4-d infusion period for the linseed and tallow treatments, respectively. Based upon the estimates of Pullen et al. (1988), the NEFA entry rate for these concentrations would be 29.7 and 35.8 mol of NEFA over the 4-d infusion period for cows weighing $735 \mathrm{~kg}$. Given that the average molecular weight of NEFA is $276 \mathrm{~g} / \mathrm{mol}$ (Bitman et al., 1984) and hepatic uptake of NEFA is $25 \%$ of the entry rate (Pullen et al., 1988), then the hepatic removal of NEFA is 2048 and $2470 \mathrm{~g}$ over the 4 -d period. Considering that fatty acids comprise $90 \%$ of TAG by weight, the linseed and tallow treatments could potentially supply 2276 and $2744 \mathrm{~g}$ of TAG, respectively, if all fatty acids were directed toward TAG synthesis. If the liver contains approximately $1.1 \mathrm{mg}$ of DNA/g of wet weight (D. G. Mashek, unpublished data, 2002) and the wet weight of the entire liver of a 735-kg cow is $9.33 \mathrm{~kg}$ (Smith and Baldwin, 1974), then the difference of $468 \mathrm{~g}$ of TAG between linseed and tallow treatments would correspond to a difference in liver TAG content of $45 \mu \mathrm{g} / \mu \mathrm{g}$ of DNA. Considering that the actual difference in liver TAG content between the linseed and tallow treatment was $6 \mu \mathrm{g} / \mu \mathrm{g}$ of DNA, the change in plasma NEFA con- centrations could account for the observed changes in hepatic TAG content.

It should be noted that the fish oil treatment had intermediate concentrations of plasma NEFA compared with tallow and linseed oil treatments. Yet, the increase in hepatic TAG concentrations was the highest for the fish oil treatment. Therefore, it is plausible that a combination of changes in plasma NEFA concentrations and in hepatic lipid metabolism may have influenced the development of fatty liver.

\section{CONCLUSIONS}

The results of this study demonstrate that intravenous administration of different lipid sources can influence the energy metabolism and the development of fatty liver. However, the current study does not identify if oils influence fatty liver development by indirect effects on extra-hepatic tissue, direct effects on hepatic tissue, or both. Treatment effects on plasma NEFA concentrations suggest that different fatty acids may influence adipose tissue metabolism, which can subsequently influence hepatic metabolism. Future research should further identify mechanisms of action, and the dosage and duration of feeding or infusing fatty acids that are needed to elicit a response.

\section{ACKNOWLEDGMENTS}

We recognize Bioproducts, Inc., Pioneer Hi-Bred International Inc., Degussa Corp., ADM Alliance Nutrition Inc., Kemin Americas, Church and Dwight Co., Inc., Land O'Lakes Inc., Diamond V Mills., and Zinpro Corp., for partial financial support of this work.

\section{REFERENCES}

Bitman, J., D. L. Wood, H. F. Tyrell, D. E. Bauman, C. J. Peel, A. C. G. Brown, and P. J. Reynolds. 1984. Blood and milk lipid response induced by growth hormone administration in lactating cows. J. Dairy Sci. 67:2873-2880.

Cadorniga-Valino, C., R. R. Grummer, L. E. Armentano, S. S. Donkin, and S. J. Bertics. 1997. Effects of fatty acids and hormones on fatty acid metabolism and gluconeogenesis in bovine hepatocytes. J. Dairy Sci. 80:646-656.

Dobbins, R. L., L. S. Szczepaniak, J. Myhill, Y. Tamura, H. Uchino, A. Giacca, and J. D. McGarry. 2002. The composition of dietary fat directly influences glucose-stimulated insulin secretion in rats. Diabetes 51:1825-1833.

Dole, V. P. 1956. A relationship between non-esterified fatty acids and glucose in plasma and the metabolism of glucose. J. Clin. Invest. 35:150-154.

Emery, R. S., J. S. Liesman, and T. H. Herdt. 1992. Metabolism of long chain fatty acids by ruminant liver. J. Nutr. 122:832-837.

Ferezou, J., and A. C. Bach. 1999. Structure and metabolic fate of triacylglycerol- and phosphoplipid-rich particles of commercial parenteral fat emulsions. Nutrition 15:44-50.

Folch, J., M. Lees, and G. H. S. Stanley. 1957. A simple method for the isolation and purification of total lipids from animal tissue. J. Biol. Chem. 226:497-509. 
Foster, L. B., and R. T. Dunn. 1973. Stable reagents for determination of serum triglycerides by a colorimetric Hantzsch condensation method. Clin. Chem. 19:338-340.

Gravena, C., P. C. Mathias, and S. J. Ashcroft. 2002. Acute effects of fatty acids on insulin secretion from rat and human islets of Langerhans. J. Endocrinol. 173:73-80.

Grum, D. E., L. R. Hansen, and J. K. Drackley. 1994. Peroxisomal $\beta$-oxidation of fatty acids in bovine and rat liver. Comp. Biochem. Physiol. B. 109:281-292.

Hultin, M., G. Bengtsson-Olivecrona, and T. Olivecrona. 1992. Release of lipoprotein lipase to plasma by triacylglycerol emulsions. Comparison to the effect of heparin. Biochim. Biophys. Acta 1125:97-103.

Hultin, M., C. Carneheim, K. Rosenqvist, and T. Olivecrona. 1995. Intravenous lipid emulsions: Removal mechanisms as compared to chylomicrons. J. Lipid Res. 36:2174-2184.

Hunnicutt, J. W., R. W. Hardy, J. Williford, and J. M. McDonald. 1994. Saturated fatty acid-induced insulin resistance in rat adipocytes. Diabetes 43:540-545.

Jorritsma, R., H. Jorritsma, Y. H. Schukken, P. C. Bartlett, T. Wensing, and G. H. Wentink. 2001. Prevalence and indicators of postpartum fatty infiltration of the liver in nine commercial dairy herds in the Netherlands. Livest. Prod. Sci. 68:53-60.

LaBarca, C., and K. Paigen. 1980. A simple, rapid, and sensitive DNA assay procedure. Anal. Biochem. 102:344-352.

Mashek, D. G., and R. R. Grummer. 2003. Effects of different long chain fatty acids on lipid metabolism and gluconeogenesis in monolayer cultures of bovine hepatocytes. J. Dairy Sci. 86:2390-2396.

National Research Council. 2001. Nutrient Requirements of Dairy Cattle. 7th rev. ed. Natl. Acad. Sci., Washington, DC.

Nestel, P. J. 1970. The depletion and restoration of post-heparin lipolytic activity in the human forearm. Proc. Soc. Exp. Biol. Med. 134:896-899.
Petit, H. V., R. J. Dewhurst, N. D. Scollan, J. G. Proulx, M. Khalid, W. Haresign, H. Twagiramungu, and G. E. Mann. 2002. Milk production and composition, ovarian function, and prostaglandin secretion of dairy cows fed omega-3 fats. J. Dairy Sci. 85:889-899.

Pullen, D. L., R. S. Emery, and N. K. Ames. 1988. Turnover of hepatic and plasma triacylglycerol in sheep. J. Anim. Sci. 66:1538-1547.

Rustan, A. C., E. N. Christiansen, and C. A. Drevon. 1992. Serum lipids, hepatic glycerolipid metabolism and peroxisomal fatty acid oxidation in rats fed omega-3 and omega- 6 fatty acids. Biochem. J. 283:333-339.

SAS Institute. 2001. User's Guide. Statistics, Version 8.2 ed. SAS Inst., Inc., Cary, NC.

Sessler, A. M., and J. M. Ntambi. 1998. Polyunsaturated fatty acid regulation of gene expression. J. Nutr. 128:923-926.

Smith, N. E., and R. L. Baldwin. 1974. Effects of breed, pregnancy, and lactation on weight of organs and tissues in dairy cattle. J. Dairy Sci. 57:1055-1060.

Strang, B. D., S. J. Bertics, R. R. Grummer, and L. E. Armentano. 1998. Effect of long-chain fatty acids on triglyceride accumulation, gluconeogenesis, and ureagenesis in bovine hepatocytes. J. Dairy Sci. 81:728-739.

Sukhija, P. S., and D. L. Palmquist. 1988. Rapid method for determination of total fatty acid content and composition of feedstuffs and feces. J. Agric. Food Chem. 36:1202-1206.

Takeuchi, H., T. Nakamoto, Y. Mori, M. Kawakami, H. Mabuchi, Y Ohishi, N. Ichikawa, A. Koike, and K. Masuda. 2001. Comparative effects of dietary fat types on hepatic enzyme activities related to the synthesis and oxidation of fatty acid and to lipogenesis in rats. Biosci. Biotechnol. Biochem. 65:1748-1754.

Vazquez-Anon, M. S., S. J. Bertics, M. Luck, and R. R. Grummer 1994. Peripartum liver triglyceride and plasma metabolites. J. Dairy Sci. 77:1521-1528.

Yeh, S. L., J. C. Tasi, and W. J. Chen. 1998. Effects of soybean oil and fish oil emulsions on glucose and lipid metabolism in streptozotocin-induced diabetic rats receiving total parenteral nutrition. J. Parenter. Enteral. Nutr. 22:297-301. 